\title{
1 AYA Testis Cancer: the Unmet Challenge
}

2 Sara Stoneham ${ }^{1}$, Matthew Murray ${ }^{2}$, Benjamin Thomas ${ }^{3}$, Max Williamson ${ }^{4}$,

3 Christopher Sweeney ${ }^{5}$, Lindsay Frazier ${ }^{6}$.

4

1. Department of Paediatrics and Child Health, University College Hospital London NHS Foundation Trust, 235 Euston Road, London.

2. Department of Pathology and Department of Paediatric Haematology and Oncology, Cambridge University Hospitals NHS Foundation Trust, Cambridge.

3. Oncology Department, Cambridge University Hospitals NHS Foundation Trust,

Cambridge, UK.

4. Life Sciences Faculty, University College London.

5. Dana-Farber Cancer Institute, Department of Medical Oncology and Division of Population Sciences, Boston, MA

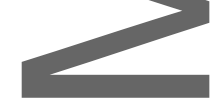

6. Dana-Farber/Boston Children's Cancer and Blood Disorders Center, MA, USA

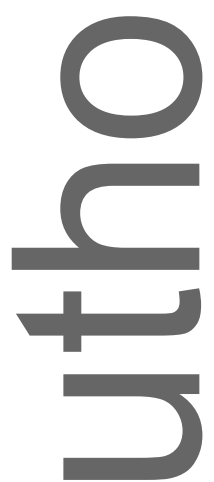

This is the authon lanuscript accepted for publication and has undergone full peer review but has not been thr onth copyediting, typesetting, pagination and proofreading process, which may lead to differences on this version and the Version of Record. Please cite this article as doi: $10.1002 / \mathrm{pbc} .27796$. 
21 Corresponding author: Dr Sara Stoneham, Department of Paediatrics and Child

22 Health, $6^{\text {Th }}$ Floor Central, 250 Euston Road, London NW1 2PG. Tel: +44203

23 4479950.Email: sara.stoneham@nhs.net.

24 Funding source. unfunded

25 Abstract 149

26 Main text: 3498

27 Figures:

28 Key words germ cell tumors, molecular biology, psychosocial, quality of life, tumor 29 biology, late effects of cancer treatment, tumors, germ cell

Abbreviations: AYA - adolescent and young adult; SMN - second malignant neoplasms; CVD - cardiovascular disease; GCT- germ cell tumours; OS - overall survival; SES- Socio-economic status; CCS - cancer specific survival; YST - yolk sac tumour; MMGCT -mixed malignant GCT; NSGCT-non-seminomatous GCT; mRNA messengerRNA; RPLND - retroperitoneal lymph node dissection; TCS -testicular cancer survivors; MRD- minimal residual disease; miRNA -microRNAs; BEP - cisplatin, etoposide and bleomycin; MaGIC- the Malignant Germ Cell International Consor40 tium.

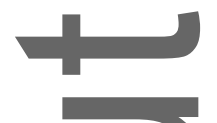


59 Abstract

60 Testis cancer is considered a rare-incidence cancer but comprises the third most

61 common cancer diagnosed within the AYA years (15-39y). Most testis cancer pa-

62 tients can anticipate a survival outcome in excess of $95 \%$. However, there are sub-

63 groups of AYA patients where outcomes are considerably worse including younger

64 adolescents, patients with certain histological subtypes, or from certain ethnic back-

65 grounds. For those cured with chemotherapy, the toxicity of treatment and burden of

66 late-effects is significant. Newer germ cell tumour - specific biomarkers may identify

This article is protected by copyright. All rights reserved. 
67 patients that do not require further treatment interventions or may detect early recur-

68 rence, potentially reducing the burden of treatment required for cure. International

69 collaboration for this rare tumour is creating the forum for trial design, where these

70 biomarker research questions are embedded. Going forward, AYA testis cancer pa-

71 tients could benefit from having a more personalised treatment plan, tailored to risk,

72 that minimises the overall burden of late-effects.

73

74

75

76

77

78

79
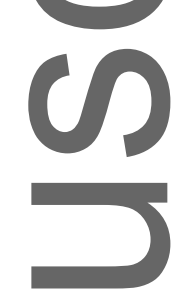

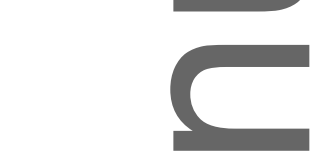

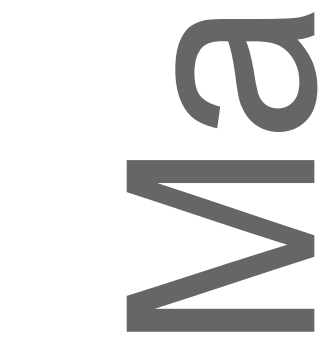

80

81

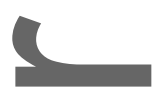

82

Introduction

83 AYA cancer patients are a unique population; presenting with age-specific cancer

84 diagnoses, differing tolerances to conventional therapies and often differing survival outcomes. (1)

86 As cancer constitutes the most common cause of disease-related deaths in this age-

87 group, health - care provision has become focused on working towards an understanding of how to provide better age-related outcomes of survival and experience of

This article is protected by copyright. All rights reserved. 
Whilst there has been much progress, particularly with regard to how to create an environment to accommodate the specific psychosocial needs for AYA patients, there is still much to learn about how to provide optimal survival outcomes.

Testicular cancer is an excellent example of this challenge. It is the most common cancer diagnosed in men under age 40 years $(\mathrm{y}) .{ }^{(3)}$ Germ cell tumours (GCT) are considered to be a curable cancer, with overall survival (OS) for all patients approaching $96 \%$. ${ }^{(4)}$ However, adolescents diagnosed with a GCT are at risk of inferior outcomes when compared with either affected children or older adults. ${ }^{(5)}$ More recent reports suggest that the broader range of AYA patients (between age 15-39y) do better than older men diagnosed with certain histological subtypes of testis cancer. ${ }^{(6)}$ So how can we ensure we identify and provide effective therapies to accommodate these subgroups of patients who are most at risk?

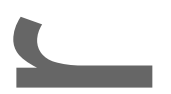

The peakincidence of GCT occurs at 30y, with the natural incidence of testis cancer spread across the entire AYA range. ${ }^{(4)}$ There is both geographical and ethnic variation in incidence within AYA, with white men in developed nations being disproportionately affected. ${ }^{(7,8)}$ However, this largest group of patients also tends to have the best outcomes. Analysis of the impact of ethnicity and socioeconomic status (SES) has shown that African American and Hispanic populations have poorer cancer spe- 
cer, we can identify another 'at risk' subgroup. What we understand less well is why

113 these young men are more vulnerable to adverse outcomes. Here, we will discuss

114 whether such outcomes can be accounted for by explanations other than poor ac-

115 cess to health care for those not insured: ${ }^{(10)}$ specifically whether diagnostic delays or

presence of more advanced disease at presentation; different histologic predomi-

nance or biologic behaviors can explain a survival gap.

The distribution and predominance of histologic subtypes of GCT varies with age. In

children <11y the most common malignant histology is yolk sac tumor (YST).

121 YST in children are generally exquisitely chemo-sensitive, and offer excellent outcomes after treatment, even in the face of advanced metastatic disease. ${ }^{(11)}$ However, within the AYA years, mixed malignant GCT (MMGCT) becomes the most common histology. (4). As age increases across the AYA range, there is relative increase in percentage of seminoma diagnoses represented, until ultimately seminoma overtakes MMGCT as the most common histological diagnosis (Figure 1). The 5 year CSS for either localized or metastatic MMGCT is less than for YST or seminoma in the same age-range. ${ }^{(4)}$

Pure choriocarcinoma, an aggressive non-seminomatous GCT (NSGCT) subtype which may present with a high burden of disease, remains rare. Hence, histologic subtype may in part contribute to the adolescent survival gap, but does not completely account for all of the discrepancy observed. ${ }^{(12)}$ 
Localized disease is by far the most common presentation of testis cancer; approximately four-fold more common than a presentation with either regional or distant metastatic disease. $^{(4)}$ (Figure 2) OS from localized disease is $95 \%$. However, in patients aged between $10-15 y,<50 \%$ patients present with localized disease. Of the remaining patients in this younger age-group, up to a third of patients are diagnosed with metastatic disease; a much higher rate than in any other age group. ${ }^{(4)}$ Veneroni et al found that adolescents had a longer symptom interval (SI) to diagnosis than children (13). For adolescents with either locally or regionally advanced GCT, delays

143 can worsen prognosis. ${ }^{(14)}$ However the relationship between SI and overall survival 144 is complex, multifactorial and must also take into account the tumour's biological behavior.

Can we identify the relationship between histologic subtypes within AYA and the burden of disease at presentation?

Seminoma presents with localized disease in up to $80 \%$ of patients, across all ages.

(4) In contrast, $<50 \%$ of AYA diagnosed with a NSGCT have localized disease. ${ }^{(4)}$ The MMGCT subtype, the most common form of NSGCT in adolescents, presents with metastatic disease three-fold more commonly than patients with seminoma. ${ }^{(4)}$ Among AYAs, choriocarcinoma was the histologic type with the most advanced stage at diagnosis with up to $60 \%$ having regional or metastatic disease, but as it is rare, it has a minimal impact on overall survival outcomes. ${ }^{(4)}$ 
157 Hence, as both histology and younger AYA age at diagnosis correlate with a greater burden of disease, there is a consequent higher burden of therapy required for cure.

How does initial burden of disease, histology and patient age relate to out-

come for AYA?

162 Overall an AYA patient with either localized disease or loco-regional disease can expect OS in excess of $95 \%$. ${ }^{(4)}$. However, an AYA patient with distant metastatic disease can anticipate a considerably lower chance of survival, between $70-80 \% .{ }^{(4)}$ For those who succumb to disease, within the AYA range, the age at which death is most likely to occur is between 20-24y. This anomaly has not changed for over 20 years. $(4)$

Amini et alfound that patients < 20y in the U.S., were managed more aggressively with surgery compared with the wider adult population, and received higher administration rates of adjuvant chemotherapy.

${ }^{(16)}$ Conceivably, the higher surgical intervention rate and more aggressive surgery performed, is explained by the higher incidence of NSGCT relative to seminoma in this age-group and a higher burden of disease at presentation. However, AYA patients generally had less co-morbidity recorded during treatment and more often received care in high volume centers, both factors normally associated with better outcomes. ${ }^{(6,17)}$ In contrast, AYA patients diagnosed with seminoma have earlier stage disease at presentation, are treated with surveillance more frequently and have a slight OS advantage over older men. ${ }^{(6)}$ Additional factors to consider which may affect patient outcomes include the less well understood role of pharmacodynamics and pharmacokinetics. Eating disorders, 
e.g. anorexia, bulimia, and obesity, all seen in the AYA age group, may have a prominent effect on drug distribution, sensitivity, efficacy, toxicity, and dosing. ${ }^{(18)}$ Hence, more intervention may translate into better outcomes, but can translate into a greater burden of potential late-effects for an individual.

cies?

GCT in pre-pubertal children generally show fundamental molecular differences to those in adult patients, despite sharing a similar histology, which suggests that basing clinical management purely on chronological age or histology alone may not provide optimal treatment strategies for AYA patients. ${ }^{(19)}$

Regarding genomic changes, gain of the short arm of chromosome $12(12 p)$ is an almost universal finding in adult testicular GCT patients. ${ }^{(20,21)}$ Gain of $12 p$ was identified in 5/18 (27\%) male pediatric GCTs in one study ${ }^{(22)}$ and $44 \%$ in another. ${ }^{(23)}$ The incidence of $12 p$ gain increased with patient age $(29 \%<5 y ; 53 \% 5-16 y){ }^{(23)}$. Thus, genomic copy number imbalances distinguish GCT subgroups primarily by age, rather than by tumor site or histology ${ }^{(19)}$. However, for the AYA population, the prognostic significance of $12 p$ gain and other genomic imbalances seen in GCTs is yet to be determined.

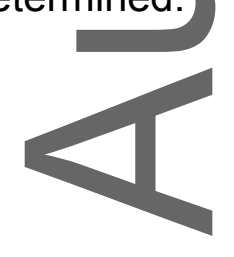

This article is protected by copyright. All rights reserved. 
202 At a transcriptomic level, pediatric GCT have a distinct protein-coding (messenger

203 RNA- mRNA) gene expression program compared with adult GCTs, irrespective of 204 tumor site ${ }^{(24)}$ Furthermore, pediatric and adult tumors with comparable histology 205 (seminoma, YST) were also segregated by global mRNA expression profiles, lending 206 weight to the suggestion that the clinical management of these entities should be dif207 ferent ${ }^{(24)}$ Interestingly, a very small number of pediatric GCTs had 'adult' profiles 208 and vice versa ${ }^{(24)}$; the significance of such findings needs to be elucidated in further studies, and interrogation of biospecimens from an AYA cohort will likely facilitate

210 this. An mRNA signature predictive of outcome has been reported in metastatic 211 NSGCT patients (median age 29y; range 15-60y), which added independent prognostic accuracy to existing risk classification systems ${ }^{(25)}$. However, translation of this multi-gene signature into clinical practice will be challenging and, it remains unclear

214 whether this predictive model would be applicable for pediatric or younger AYA (1324y) populations. $(19,26)$

Do AYA have suboptimal treatment strategies/cure vs. Quality of life for AYA have we got the balance right?

219 Adult testis cancer is viewed as the success story for a curable cancer. However, 220 this cure is not without significant cost in the longer term. The burden of late effects

221 is both wide in range and significant in impact for all men requiring adjuvant treatment. They include an increased risk of second malignant neoplasm (SMN); early onset cardiovascular disease (CVD); hypogonadism; infertility; peripheral neurotoxi- 
city; tinnitus and hearing loss; renal toxicity; pulmonary toxicity; fatigue; and anxiety and depression.

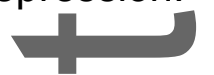

After mortality, fertility is the second most common concern for patients with cancer.

(27) This is of particular concern for younger AYA patients diagnosed and treated for cancer at a time in life when many have not made choices around starting a family, let alone completion. The link between reduced fertility and cancer starts at diagnosis and up to to $50 \%$ of post-orchiectomy patients have been shown to have decreased sperm counts, with some patients also having low sperm motility and abnormal sperm cells. ${ }^{(28)}$

Further components of testicular cancer therapy, namely retroperitoneal lymph node dissection (RPLND), radiotherapy and chemotherapy, all come with differing fertility risks. For patients requiring chemotherapy for cure, the cumulative dose of cisplatinbased treatment is directly associated with the risk of infertility and achievement of paternity. $(29,30,31$,$) Conversely, the use of carboplatin-based regimens, directly com-$ pared with eisplatin, has been shown to be associated with fourfold greater recovery to normal sperm counts. ${ }^{(32)}$ The majority of AYA patients will be diagnosed with a NSGCT and will receive 'adult' BEP.

Up to athird of patients with NSGCT metastatic disease may require consideration of a RPLND following chemotherapy. RPLND is associated with significant potential morbidity, both in the peri-operative period and in the long-term. In the postchemotherapy setting, the gold standard for surgery remains a bilateral template dis- 
247 section via an open approach. ${ }^{(33)}$ If the retroperitoneal postganglionic sympathetic

248 nerves are damaged intra-operatively, this surgical procedure carries the risk of in-

249 ducing retrograde ejaculation in up to $9 \%$ of patients. ${ }^{(34)}$

250 Radiotherapy (RT) has played an important adjuvant role in advanced stage semi-

251 noma therapy for many years, and for most patients, there is recovery of normal

252 spermatogenesis within 24 months of end of treatment ${ }^{(30,35)}$. In long-term follow-up,

253 when compared with a surgery-only cohort, there appears to be no significant impact

254 on spermatogenesis. ${ }^{(30,35)}$ Thus overall, RT is less likely to be implicated in any loss

255 of fertility for AYA patients, as fewer AYA patients will require RT.

257 Hypogonadism contributes to the risk of infertility. Causes of hypogonadism include

orchiectomy itself, chemotherapy, radiotherapy and any underlying testicular dys-

genesis syndrome. The additional side effects of hypogonadism include reduced

sexual functioning, depression, fatigue, loss of muscle mass and osteoporosis. Fur-

thermore, the known association between the metabolic syndrome and CVD as a direct result of hypogonadism adds substantially to the burden of late-effects. ${ }^{(36)}$

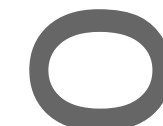

264 The risk of early onset CVD is of particular concern. The relative risk of CVD in patients treated with chemotherapy is $1.4-7.1$ fold higher compared with the general population or those patients undergoing surgery alone. ${ }^{(36,37,38)}$ Hypogonadism, together with chemotherapy-induced vascular injury and chemotherapy-related disturbance of metabolic homeostasis, combine ${ }^{(39)}$ to increase CVD mortality risk. In a 
population based study, Fung et al described patients appearing to be at most risk

270

271

272

273

274

275

276

277

278

279

280

281

282

283

284

285

286

291

within the first year off treatment, with a calculated 5.3-fold risk of mortality. ${ }^{(40)}$

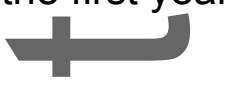

SMN constitutes a significant cause of morbidity and mortality. Post-chemotherapy, there is an increased risk of both solid and leukemic SMNs. Kollmansberger et al reported that the 5 year cumulative incidence of secondary leukemia after a cumulative etoposide dose of $<2000 \mathrm{mg} / \mathrm{m}^{2}$ and $>2000 \mathrm{mg} / \mathrm{m}^{2}$ was approximately $0.5 \%$ and $2.0 \%$, respectively. ${ }^{(41)}$ Similarly, when Fung et al reviewed the risk of solid tumor SMN, a 1.4-fold increase risk for those who had received chemotherapy compared with those who underwent surgery alone was identified. ${ }^{(42)}$ Therefore, not only the choice of chemotherapy drugs, but also the dosing of these drugs, appears to be important.

Long-term renaldysfunction has been directly associated with cumulative dosing of cisplatin. (43) Up to $40 \%$ of testicular cancer survivors (TCS) experience symptoms of peripheral neuropathy during and/or after chemotherapy. ${ }^{(44,45)}$ Non-fatal pulmonary toxicity has been reported between $7-21 \%$ of TCS. ${ }^{(46,47)}$ Risk factors for restrictive lung disease included cisplatin dose and increasing age, after adjusting for bleomycin, etoposide and vinblastine exposure. ${ }^{(48)}$ For TCS treated with chemotherapy, there was a higher mortality rate from all respiratory diseases when compared with the general population. ${ }^{(49)}$

Ototoxicity secondary to cisplatin may also have a significant impact on quality-oflife. ${ }^{(50,51)}$ Bokemeyer et al reported symptomatic ototoxicity in $20 \%$ of testicular cancer survivors. ${ }^{(52)}$ Tinnitus was the most reported symptom in $59 \%$ patients, but

This article is protected by copyright. All rights reserved. 
$23 \%$ reported both tinnitus and hearing loss together. Dose was important, with $50 \%$ of patients receiving $>400 \mathrm{mg} / \mathrm{m}^{2}$ cisplatin experiencing persistent ototoxicity. ${ }^{(52)}$

One of the late effects TCS find most distressing is fatigue; it is often the most fre-

quently reported concern in long-term follow-up.

(53) The prevalence of depression in up to $20 \%$ of TCS has been reported widely ${ }^{(54,55,56, \text { and } 57)}$ with anxiety significantly associated with younger age at diagnosis. ${ }^{(55)}$ AYA patients are already known to be more likely to suffer psychological problems after a cancer diagnosis and greater dif-

ficulty in retaining employment or maintaining education. $(58,58,60)$

Many AYAs with cancer report that their cancer makes them feel 'abnormal'. ${ }^{(61)}$ TCS describe difficulty both with romantic partnerships and support. ${ }^{(62)}$ Anxieties around body image and masculinity arise when changes in appearance (e.g. scarring, loss of hair/body parts etc.) result in diminishment of sexual attractiveness. ${ }^{(61,62)}$ Bellizzi et al, in the AYA HOPE study, showed that over $50 \%$ of TCS reported they felt like 'damaged goods' due to surgical scars and loss of a testicle and had concerns about their ability to have children. $(60,61,62)$

Although a cancer diagnosis may be disruptive to normal social maturation for an cancer could not understand how the experience had shaped their life views on maturing and growing up. They considered the experience provided them with a unique, but different, outlook on life, marriage and parenthood compared with their peers. ${ }^{(61)}$ Hence for a common cancer in this AYA age range, for patients with many life years

314 ahead, the burden of late-effects can be profound. 
316 What can we do to reduce burden of therapy? Personalizing the treatment 317 plan.

318 A better understanding of the absolute need for surgery, radiotherapy and intensity

319 of chemotherapy regimens could mitigate against some late-effects. Minimal residual 320 disease (MRD) testing by highly sensitive PCR techniques has been transformative for patients with ALL; allowing a more elegant risk stratification to inform the burden of therapy The emergence of microRNAs (miRNA) as a biomarker of disease could potentially help risk-stratify the burden of therapy required for cure in a way analogous to MRD for ALL patients i.e. allowing understanding of 'molecular remission' and no requirementfor any further treatment intervention. MiRNAs are short, non-coding RNAs that modulate protein-coding gene expression, through interactions with specific binding sites in the 3' untranslated regions of messenger RNAs. ${ }^{(66)}$. MiRNAs are dysregulated in cancer, acting either as oncogenes or tumor suppressor genes. ${ }^{(67)}$

330 In GCTs, the most striking finding was universal miR-371 373 and miR-302/367 cluster over-expression in all malignant tumors, regardless of patient age (pediatric/AYA/adult), histologic subtype (YST/ seminoma) or anatomic site (gonadal/extragonadal). ${ }^{(66)}$ Expression levels of just the eight main miRNAs from these two clusters accurately separated >100 malignant GCTs from non-malignant samples, suggesting that these miRNAs could offer high sensitivity and specificity as malignant GCT biomarkers ${ }^{(66)}$.

This article is protected by copyright. All rights reserved. 
Serum miRNAs have also been shown to be useful longitudinally for early sensitive detection of malignant recurrence in stage I disease and disease-monitoring following initiation of chemotherapy. ${ }^{(68)}$ Serum miRNA testing and validation in prospective

340 clinical trials (e.g. the Children's Oncology Group's trial AGCT1531) is now under

341 way, heralding an opportunity for non-invasive monitoring and reduced use of serial

342 CT scans with consequent radiation exposure during treatment and follow-up. ${ }^{(69)}$

343 The potential methods of decreasing the morbidity of surgery in the future are likely

344 to involve a decrease in the extent of surgical dissection, and the increased utiliza-

345 tion of minimally invasive approaches, particularly robot-assisted RPLND. These

346 methods are of particular significance in the AYA population. European and North

347 American studies in high volume centers have shown that the use of modified unilateral templates for selected cases did not result in any recurrences within the field of a bilateral template dissection and did not compromise oncological outcomes, exemplifying that when RPLND is a fundamentally important for cure, referral to high volume centres with experienced uro-oncology surgeons is paramount. ${ }^{(70,71)}$ Robotic RPLND in the post-chemotherapy setting is increasingly utilized. Small series have shown significant decreases in peri-operative morbidity, rates of retrograde ejaculation and hospital length of stay without compromise of oncological outcomes although long-term follow-up is not yet present. $(72,73,74)$

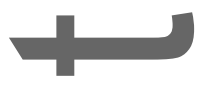

357 For those AYA patients where chemotherapy remains essential for cure, we have a responsibility to develop less toxic but equally effective treatment regimens. Adult BEP chemotherapy (cisplatin, etoposide and bleomycin) remains the gold standard 
treatment. ${ }^{(75)}$ Carboplatin is a platinum agent that has not been demonstrated to

361 have the same long-term toxicity profile as cisplatin. Historically, carboplatin regimens have been tested against cisplatin in the hope that carboplatin may provide equally effective survival outcomes but with less morbidity. $(76,77,78)$ These trials had concluded it was less effective than cisplatin. Recent reviews comparing these and other cisplatinand carboplatin outcomes, suggests we should re-consider its use across all ages, as inadequate dosing and frequency of delivery could account for the discrepancy in outcomes documented in the era before the use of stem-cell factor support. ${ }^{(79,80)}$ Pharmacogenomics studies may further help finesse decision making.

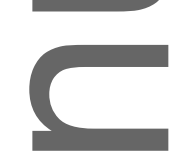

As a result of the above, the international GCT community needs to continue to ad-

374 vocate for all GCT patients, but in particular for AYA patients with testicular cancer

375 where arguably much more remains unknown and unresolved. MaGIC (the Malignant Germ Cell International oonsortium; https://www.magicconsortium.com/) is an

377 international collaboration comprising clinicians and scientists from pediatric, medi-

378 cal, gynecological, clinical oncology and allied disciplines. International platforms

379 such as MaGIC can begin to address geographic and ethnic variation in outcomes 380 and ensure biology is embedded in new trial development. This strategy should allow us to locate these vulnerable subgroups of patients, reduce the burden of therapy and engage the groups of patients that are most at risk of late-effects in tailored re- 
search programs. More locally, discussion of teenage GCT patients should always

384 take place in a disease-specific multidisciplinary meeting with combined medical and paediatric oncology representation. This will facilitate sharing of expertise, promote enrolment into international trials open to AYA patients and adherence to national guidance to support safe delivery of care and minimize treatment related mortality.

\section{Conclusion}

392 The incidence of testicular cancer is increasing across all ages within the AYA spec393 trum (13-39y). Compared with older adult patients, AYA patients present with a higher burden of disease and with more NSGCT histologies which require more intensive treatment for cure; this inevitably translates into an increased burden of late effects.

By contrast, for men aged $>40 y$, the prevalence remains stable. Thus, for those patients with the most life years left to live, the numbers of patients requiring the most morbid treatment are increasing.

The identified miRNA signature, applicable across all patient ages, offers the potential for a universal test for diagnosis and disease-monitoring. Although the genomic

401 and protein-coding gene molecular differences observed between pediatric and adult 402 GCTs

403 ' may well be triggered by puberty, most, but not all, AYA GCT are likely to be 'adult' 404 tumors biologically, the lack of focus on this cohort to date makes this largely an as405 sumption. Consequently, clinical management based simply on chronological patient 
406

407 younger AYA group (13-24y), may alleviate these challenges and facilitate more per408

409

410

411

412

415

416

417

418

419

420

421

422

423

424

425

426

427

428

429

430

age may well be suboptimal. Future research focused on AYAs, particularly the sonalized clinical management including removal of disparities in access to health care as an issue. Moreover, such work may also allow more accurate prognostic risk groups to be defined and assist the development of novel therapies that have increased efficacy in poor-prognosis tumors and/or cause less long-term toxicity in good-prognosis patients. All this will be best achieved within a collaborative, international forum.
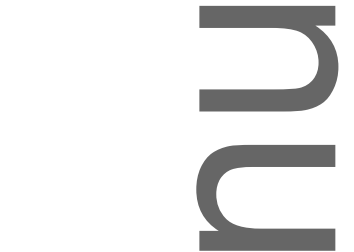

\section{Conflict of Interest Statement:}

\section{(}

1. Dr Lindsay Frazier - clinical advisory board, Decibel Advisory Board.

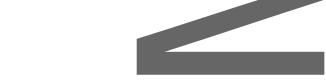

Acknowledgments:

2

\section{St Baldrick's Foundation}

(1)

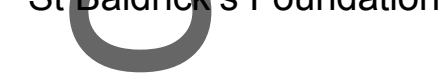

(1)

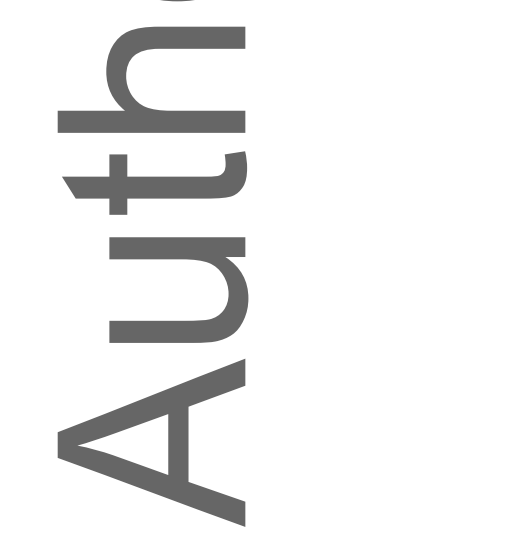

This article is protected by copyright. All rights reserved. 
432

433

434

435

436

437

438

439

440

441

442

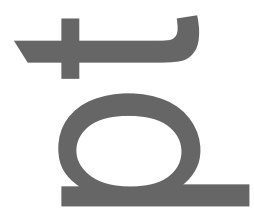

36
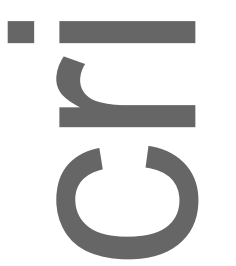

443

444

445

446



447

448

449

450

451

452

453

454

455

456
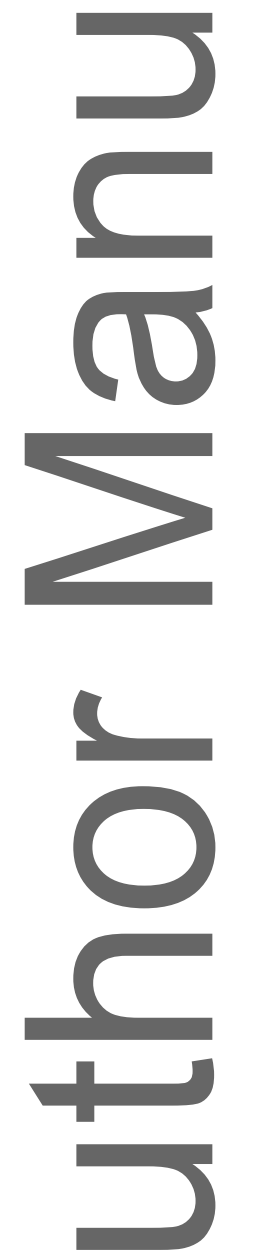

This article is protected by copyright. All rights reserved. 
460

461

462

463

464

465

466

467

468

469

470

471

472

473

474

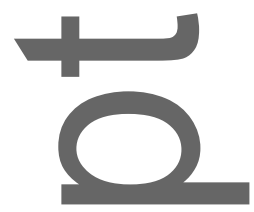

$$
\square
$$
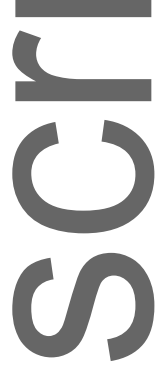

475

476

477 References:

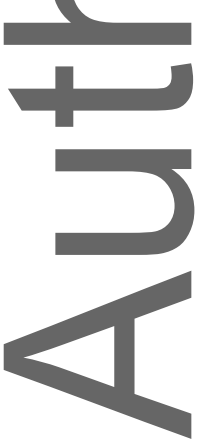

This article is protected by copyright. All rights reserved. 
478 1. Bleyer A, 'Adolescent and Young Adult oncology: the first A,' Paediatric Hematolo-

479 gy and Oncology, Vol.24, no.5, pp. 325-336, 2007.

480

2. Schmidt $C$, Lack of progress in teen and young adult cancers concerns researchers, prompts study, 'Journal of the National Cancer Institute, vol. 98, no.24, pp.

3. Barr RD, Ries LA, Lewis DR, Harlan LC, Keegan TH, Pollock BH, Bleyer WA; US 486 National Cancer Institute Science of Adolescent and Young Adult Oncology Epi487 demiology Working Group. Incidence and incidence trends of the most frequent cancers in adolescent and young adult Americans, including "nonmalignant/noninvasive" tumors. Cancer. 2016 Apr 1;122(7):1000-8.

490

4. Surveillance, Epidemiology, and End Results (SEER) Program

492 (www.seer.cancer.gov) SEER*Stat Database: Incidence - SEER 18 Regs Re-

493 search Data + Hurricane Katrina Impacted Louisiana Cases, Nov 2017 Sub (2000-

494 2015) <Katrina/Rita Population Adjustment> - Linked To County Attributes - Total

495 U.S., 1969-2016 Counties, National Cancer Institute, DCCPS, Surveillance Re496 search Program, released April 2018, based on the November 2017 submission.

5. Cost NG, Lubăhn JD, Adibi M, Romman A, Wickiser JE, Raj GV, Sagalowsky AI, Margulis V. A comparison of pediatric, adolescent, and adult testicular germ cell malignancy. Pediatr Blood Cancer. 2014 Mar;61 (3):446-51. 
6. Stokes W, Amini A, Maroni PD, Kessler ER, Stokes C, Cost CR, Greffe BS,

503 Garrington TP, Liu AK, Cost NG. Patterns of care and survival outcomes for

504 adolescent and young adult patients with testicular seminoma in the United States:

505 A National Cancer Database analysis. J Pediatr Urol. 2017 Aug;13(4):386

506

507

7.Znaor A, Lortet-Tieulent J, Laversanne M, Jemal A, Bray F. International testicular 508 cancer incidence trends: generational transitions in 38 countries 1900-1990.

509 Cancer Causes Control. 2015 Jan;26(1):151-8.

510

511

8. Chien FL, Schwartz SM, Johnson RH. Increase in testicular germ cell tumor

512 incidence among Hispanic adolescents and young adults in the United States.

513 Cancer. 2014 Sep 1;120(17):2728-34. doi: 10.1002/cncr.28684.

514

515 9. Biggs ML, Schwartz SM. Differences in testis cancer survival by race and ethnicity:

516 a population-based study, $1973-1999$ (United States). Cancer Causes Control.

5172004 Jun;15(5):437-44

518

519 10. . Markt SC, Lago-Hernandez CA, Miller RE, Mahal BA, Bernard B, Albiges L,

520 Frazier LA, Beard CJ, Wright AA, Sweeney CJ. Insurance status and disparities in

521 disease presentation, treatment, and outcomes for men with germ cell tumors.

$522 \quad$ Cancer. 2016 Oct 15;122(20):3127-3135. 
524 11. Faure Conter C, Xia C, Gershenson D, Hurteau J, Covens A, Pashankar F, 525 Krailo M, Billmire D, Patte C, Fresneau B, Shaikh F, Stoneham S, Nicholson J, 526 Murray M, Frazier AL. Ovarian Yolk Sac Tumors; Does Age Matter? Int J Gynecol 527 Cancer. 2018 Jan;28(1):77-84

12. DeRouen MC, Mujahid M, Srinivas S, Keegan TH. Disparities in Adolescent and Young Adult Survival After Testicular Cancer Vary by Histologic Subtype: A Population-Based Study in California 1988-2010.,J Adolesc Young Adult Oncol. 2016 Mar;5(1):31-40. doi: 10.1089/jayao.2015.0041. Epub 2015 Nov 18.

13. Veneroni L, Mariani L, Lo Vullo S et al. Symptom interval in pediatric patients with solid tumors: adolescents are at greater risk of late diagnosis.

539 14. Ferrari A, Lo Vullo S, Giardiello D, Veneroni L et al The Sooner the Better?

540 How Symptom Interval Correlates With Outcome in Children and Adolescents With

541 Solid Tumors: Regression Tree Analysis of the Findings of a Prospective Study.

542 Pediatr Blood Cancer. 2016 Mar;63(3):479-85. doi: 10.1002/pbc.25833

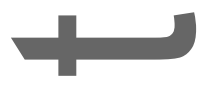

544 15. Barr RD. "Delays" in diagnosis: a misleading concept, yet providing opportuni-

545 ties for advancing clinical care. J Pediatr Hematol Oncol. 2014 Apr;36(3):169-72. doi: $10.1097 / \mathrm{MPH}$

This article is protected by copyright. All rights reserved. 
549 16. Amini A, Waxweiler TV, Maroni PD, Kessler ER, Cost CR, Greffe BS, Garring550 ton TP, Liu AK, Cost NG. Survival outcomes of adolescent and adult patients with 551 non-seminomatous testicular germ-cell tumors: A population-based study. J Pedi552 atr Urol 2016 Dec; 12(6):405.

553

554

555 17. Albritton $\mathrm{KH}$, Coccia P. Influencing referral of adolescents and young adults 556 with cancer to sites with higher rates of trial enrollment. Pediatrics. 2014 Jun;133

557 Suppl 3.S104-8. doi: 10.1542/peds.2014-0122E

18. Veal GJ, Hartford CM, Stewart CF. Clinical pharmacology in the adolescent 560 oncology patient. J Clin Oncol. 2010 Nov 10;28(32):4790-9.

561

562

19. Collinson K, Murray MJ, Orsi NM, et al. Age-related biological features of germ cell tumors. Genes Chromosomes Cancer 2014:53(3):215-227.

564

565

566

567

20. Atkin NB, Baker MC. Specific chromosome change, i(12p), in testicular tumours? Lancet 1982:2(8311):1349.

21. Atkin NB, Baker MC. i(12p): specific chromosomal marker in seminoma and malignant teratoma of the testis? Cancer Genet Cytogenet 1983:10(2):199-204.

This article is protected by copyright. All rights reserved. 
574 22. Bussey KJ, Lawce HJ, Himoe E, et al. Chromosomes 1 and 12 abnormalities 575 in pediatric germ cell tumors by interphase fluorescence in situ hybridization. Can$576 \quad$ cer Genetics and Cytogenetics 2001:125(2):112-118.

577

24. Palmer RD, Barbosa-Morais NL, Gooding EL, et al. Pediatric malignant germ

583 cell tumors show characteristic transcriptome profiles. Cancer research

$584 \quad 2008: 68(11): 4239-4247$.

585

586 587

25. Korkola JE, Houldsworth J, Feldman DR, et al. Identification and validation of a gene expression signature that predicts outcome in adult men with germ cell tumors. Journal of clinical oncology : official journal of the American Society of Clinical Oncology 2009:27(31):5240-5247.

590

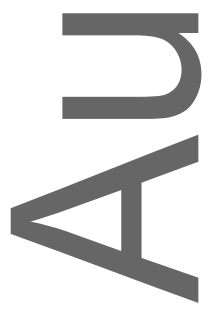

This article is protected by copyright. All rights reserved. 
26. Chen KS, Fustino NJ, Shukla AA, et al. EGF Receptor and mTORC1 Are

592 Novel Therapeutic Targets in Nonseminomatous Germ Cell Tumors. Mol Cancer

593 Ther. 2018 May;17(5):1079-1089.

594

595

27. Loscalzo MJ, and Clark KL. 'The Psychosocial context of cancer related infer596 tility,' Cancer Treatment and Research, vol. 138, pp. 180-190, 2007.

597

598

28. Fossa SD, Abyholm T, and Aakvaag A. 'Spermatogenesis and hormonal sta599 tus after orchiectomy for cancer and before supplementary treatment, 'European $600 \quad$ Urology, vol. 10, no. 3 pp. 173-177, 1984.

601

602

29. Brydoy, M, Fossa SD, Klepp O, et al., 'Paternity following treatment for tes603 ticular cancer,' Journal of the National Cancer Institute, vol. 97, no.21, pp.1580-

604

605

606

30. Brydoy, M, Fossa SD, Klepp O, et al. 'Paternity and testicular function among 607 testicular cancer survivors treated with two to four cycles of cisplatin -based chem-

608

609

610 31. Brydoy, M, Fossa SD, Klepp O, et al. "Sperm counts and endocrinological 611 markers of spermatogenesis in long-term survivors of testicular cancer,' British 612 Journal of Cancer, vol. 107, no.11, pp. 1833-1839, 2012.

613

This article is protected by copyright. All rights reserved. 
614 32. Lampe $\mathrm{H}$, Horwich $\mathrm{A}$, Norman A, et al., Fertility after chemotherapy for testicu-

615 lar germ cell cancers, 'Journal of Clinical Oncology, vol. 15, no.1, pp. 239-245, 6161997.

33. Large MC, Sheinfeld J, Eggener SE, Retroperitoneal lymph node dissection: reassessment of modified templates. BJU Int 2009; 104: 1369-75.

620

34. Beck SD, Bey AL, Birhle R, et al., 'Ejaculatory status and fertility rates after

622 primary retroperitoneal lymph node dissection, 'Journal of urology, vol. 184, no.5, pp. 2078-2080, 2010.

35. Gandino I, Sgro P, Lombardo F, et al., "Effect of chemo- or radiotherapy on sperm parameters of testicular cancer patients,' Human Reproduction, vol. 21, no.

36. Christensen JF, Bandak M, Campbell A et al. 'Treatment-related cardiovascu11, pp. 2882-2889, 2006. lar late effects and exercise training countermeasures in testicular germ cell cancer survivorship',Acta Oncologica, vol. 54, no.5, pp.592-599.

37. Meinardi-MT, Gietema JA, van der Graaf WT et al., 'Cardiovascular morbidity 634 in long-term survivors of metastatic testicular cancer, ' Journal of Clinical Oncology, vol. 18, no.8, pp. 17245-1732, 2000. 
38. Haughnes HS, Wethal T, Aass N, et al., 'Cardiovascular risk factors and mor-

638 bidity in long-term survivors of testicular cancer: a 20-year follow up study,' Journal 639 of Clinical Oncology, vol. 28, no.30, pp. 4649-4657, 2010.

640

39. Huddart, RA, Norman A, Shahidi M, et al., "Cardiovascular disease as a longterm complication of treatment for testicular cancer,' Journal of Clinical Oncology,

40. Fung $\mathrm{C}$, Fossa SD, Milano MT et al., 'Cardiovascular disease mortality after chemotherapy or surgery for testicular non-seminoma: a population -based study, ' Journal of Clinical Oncology, vol. 33, no. 28, pp. 3105-3115, 2015.

650

41. Kollmannsberger C, Hartmann JT, Kanz L, et al., 'Therapy-related malignancies following treatment of germ cell cancer, 'International Journal of Cancer, vol.

653

654

42. Fung c, Fosa SD, Milano MT et al., 'Solid tumours after chemotherapy or sur83, no.6, pp. 860-863, 1999.

657 Oncology, vol. 31, no. 30, pp. 3807-3814, 2013.

658

This article is protected by copyright. All rights reserved. 
659 43. Fossa SD, Aass N, Winderen M, et al., 'Long-term renal function after treat660 ment for malignant germ-cell tumours. Annals of Oncology vol. 13, no. 2, pp. 222661

662 228,2002

44. Glendenning JL, Barbachano Y, Norman AR et al., 'Long-term neurologic and 664 peripheral vascular toxicity after chemotherapy treatment of testicular cancer, ‘

665 Cancer vol. 116, no. 10, pp. 2322-2331, 2010.

666

Brydoy M.COldernburg J, klepp O et al., 'Observational study of prevalence of long667 term raynaud-like phenomena and neurological side effects in testicular cancer survivors, ' Journal of the National Cancer Institute, vol. 101, no.24, pp. 1682-1695, 669 2009.

45. O'Sullivan JM, Huddart RA, Norman AR, et al., 'Predicting the risk of bleomy671 cin lung toxicity in patients with germ cell tumours Annals Oncology, vol. 14, no.1, pp. 91-96, 2003.

673

674 46. Dearnaley DP, Horwich A, A'Hern R et al., 'Combination chemotherapy with 675 bleomycin, etoposide, and cisplatin (BEP) for metastatic teratomas: long-term fol676 low-up. European Journal of Cancer, vol. 27, no. 6, pp. 684-691, 19991

677 678

679 680

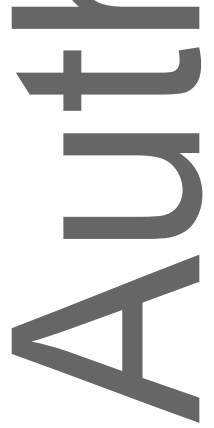

This article is protected by copyright. All rights reserved. 
681 47. Haughnes HS, Aaass N, Fossa SD, et al., 'Pulmonary function in long-term

682 survivors of testicular cancer,' Journal of Clinical Oncology, vol. 27, no. 17, pp.

683

684

685

48. Fossa SD, Gilbrt E, Dores GM et al., 'Non-cancer cases of death in survivors

686

687

688

689

49. Hyams AV, Hay-McCutcheon M, Scogin F, 'Hearing and quality of life in older 690

691

692

50. Matkin, ND, Wilcox MS, 'Considerations in the education of children with hear-

693

694

51. adults. Journal Clinical Psychology, J une 2018..

695

696

52. Bokemeyer C, Berger CC, Hartmann JT, et al., 'Analysis of risk factors for

697 cisplatin-induced ototoxicity in patients with testicular cancer. British Journal Can698 cer, vol. 77, no.8, pp. 1355-1362, 1998.

699

700

53. Oechste K, Hartmann M, Mehnert A et al., 'Symptom Burden in long-term 701 germ cell tumour survivors,' Support Cancer Care, vol. 24, no.5, pp. 2243-2250, 2016.

This article is protected by copyright. All rights reserved. 
704

705

706

707

708

709

710

711

712

713

714

715

716

717

718

719

720

721

722

723

724

54. Dahl AA, Haaland CF, Mykletun A et al., "Study of anxiety disorder and depression in long-term survivors of testicular cancer, ' Journal of Clinical Oncology, vol. 23, no.10, pp. 2389-2395, 2005.

55. Vehling S, Mehnert A, Hartmann M, et al., 'Anxiety and depression in longterm testicular germ cell tumour survivors,' General Hospital Psychiatry, vol. 38, pp. 21-25, 2016.

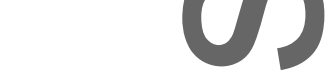

56. Shinn EH, Basen-Engquist K, Thornton B et al., 'Health behaviors and depressive symptoms in testicular cancer survivors, 'Urology, vol. 69, no. 4, pp. 748753,2007



57. Smith AB, Butow P, Olver I et al., 'The prevalence, severity, and correlates of psychological distress and impaired health-related quality of life following treatment for testicular cancer: a survivorship study, ' Journal of cancer survivorship, vol. 10, no.2, pp. 223-233, 2016.

58. Parsons HM, Harlan LC, Lynch CF et al., Impact of cancer on work and education among adolescent and young adult cancer survivors, Journal of Clinical Oncology, vol. 30 no. pp. 2393-2400, 2012

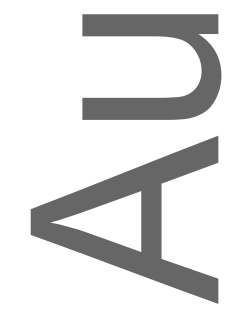

This article is protected by copyright. All rights reserved. 
59. Smith AW, Bellizzi KM, Keegan TH et al., 'Health- related quality of life of adolescent and young adult cancer patients in the United states: the AYA HOPE study, Frontiers in Oncology, vol. 3, no.75, pp.

60. Bellizzi KM, Smith A, Schmidt S, et al. Adolescent and Young Adult Health Outcomes and Patient Experience (AYA HOPE) Study Collaborative Group. Positive and negative psychosocial impact of being diagnosed with cancer as an adolescent or young adult. Cancer. 2012; 118:5155-5162.

733

61. Carpentier MY, Fortenberry JD, Ott MA, Brames MJ, Einhorn LH. Perceptions 735 of masculinity and self-image in adolescent and young adult testicular cancer survivors: implications for romantic and sexual relationships. Psycho-oncology. 2011; 20:738-745. [PubMed: 20878864]

62. Love B, Thompson CM, Knapp J. The need to be Superman: the psychosocial support challenges of young men affected by cancer. Oncol Nurs Forum. 2014;

745 64. Psychology Interactive. [July 2, 2015] Social development: why it is important

63. Grinyer A. The biographical impact of teenage and adolescent cancer. Chronic IIIn. 2007; 3:265- 277. 747 and how to impact it. http://www.edpsycinteractive.org/papers/socdev.pdf.

This article is protected by copyright. All rights reserved. 
65. Nunes V, Cazzaniga G, Biondi A An update on PCR use for minimal residual

749 disease monitoring in acute lymphoblastic leukemia. Expert Rev Mol Diagn. 2017

750

751

752

66. Palmer RD, Murray MJ, Saini HK, et al. Malignant germ cell tumors display commonmicroRNA profiles resulting in global changes in expression of messen-

67. Shenouda S, Alahari S. MicroRNA function in cancer: oncogene or a tumor ger RNA targets. Cancer research 2010:70(7):2911-2923.

758 suppressor? Cancer Metastasis Rev 2009:28(3-4):369-378.

759

68. Murray MJ, Halsall DJ, Hook CE, et al. Identification of microRNAs From the 760 miR-371 373 and miR-302 clusters as potential serum biomarkers of malignant germ cell tumors. American Journal Clinical Pathology 2011:135(1):119-125.

69. Murray MJ, Bell E, Raby KL, et al. A pipeline to quantify serum and cerebro764 spinal fluid microRNAs for diagnosis and detection of relapse in paediatric malignant germ-cell tumours. Br J Cancer 2016:114(2):151-162

70. Cho JS, Kaimakliotis, Cary C, Masterson TA, Beck S, Foster R. Modifed retroperitoneal lymph node dissection for post-chemotherapy residual tumour: a long769 term update. BJU Int 2001; 120(1): 104-108.

770

This article is protected by copyright. All rights reserved. 
772 71. Heidenreich A, Pfister D, Witthuhn R, Thüer D, Albers P. Postchemotherapy

773 retroperitoneal lymph node dissection in advanced testicular cancer: radical or

774 modified template resection. Eur Urol. 2009; 55(1):217-24

775 72. Stepanian S, Patel M, Porter J. Robot-assisted Laparoscopic Retroperitoneal

776 Lymph Node Dissection for Testicular Cancer: Evolution of the Technique. Eur

$777 \quad$ Urol 2016, 70:661-227.

778

779

73. Cheney SM, Andrews PE, Leibovich BC, Castle EP. Robot-assisted retroperi780 toneal lymph node dissection: technique and initial case series of 18 patients. BJU 781 Int 2015, 115:114-20.

782

783

74. Thomas BC, Lee EWYL, Coret HM. Robotic retroperitoneal lymph node dis-

784 section for non-seminomatous germ cell tumour in a centralised post-

785 chemotherapy surgical practice. BJU Int 2018; 121 (S1): 27.

786

787 75. Einhorn LH, Williams SD. Combination chemotherapy with cis-

788 dichlorodiammineplatinum(II) and adriamycin for testicular cancer refractory to vin-

789 blastine plus bleomycin. Cancer Treat Rep. 1978 Sep;62(9):1351-3.

790

791 76. Bokemeyer $\mathrm{C}$, Kohrmann O, Tischler J, et al. A randomized trial of cisplatin, 792 etoposide and bleomycin (PEB) versus carboplatin, etoposide and bleomycin

This article is protected by copyright. All rights reserved. 
(CEB) for patients with 'good-risk' metastatic non-seminomatous germ cell tumors.

$794 \quad$ Ann Oncol 1996;7:1015-102.

795

77. Horwich A, Sleijfer DT, Fossa SD, et al. Randomized trial of bleomycin, etoposide, and cisplatin compared with bleomycin, etoposide, and carboplatin in good-prognosis metastatic nonseminomatous germ cell cancer: A multi-

799 institutional Medical Research Council/European Organization for Research and Treatment of Cancer Trial. J Clin Oncol 1997;15:1844-1852.

801

78. Bajorin DF, Sarosdy MF, Pfister DG, et al. Randomized trial of etoposide and 803 cisplatin versus etoposide and carboplatin in patients with good-risk germ cell tumors: A multi -institutional study. J Clin Oncol 1993; 11:598-606.

805

79. ShaikhF, Nathan PC, Hale J, et al..Is there a role for carboplatin in the treat807 ment of malignant germ cell tumors? A systematic review of adult and pediatric tri808 als. Pediatr Blood Cancer. 2013 Apr;60(4):587-92.

809

80. Frazier AL, Stoneham S, Rodriguez-Galindo C, Et al. Comparison of car-

811 boplatin versus cisplatin in the treatment of paediatric extracranial malignant germ 812 cell tumours: A report of the Malignant Germ Cell International Consortium. Eur J

813 Cancer. 2018 Jul; 98:30-37. 


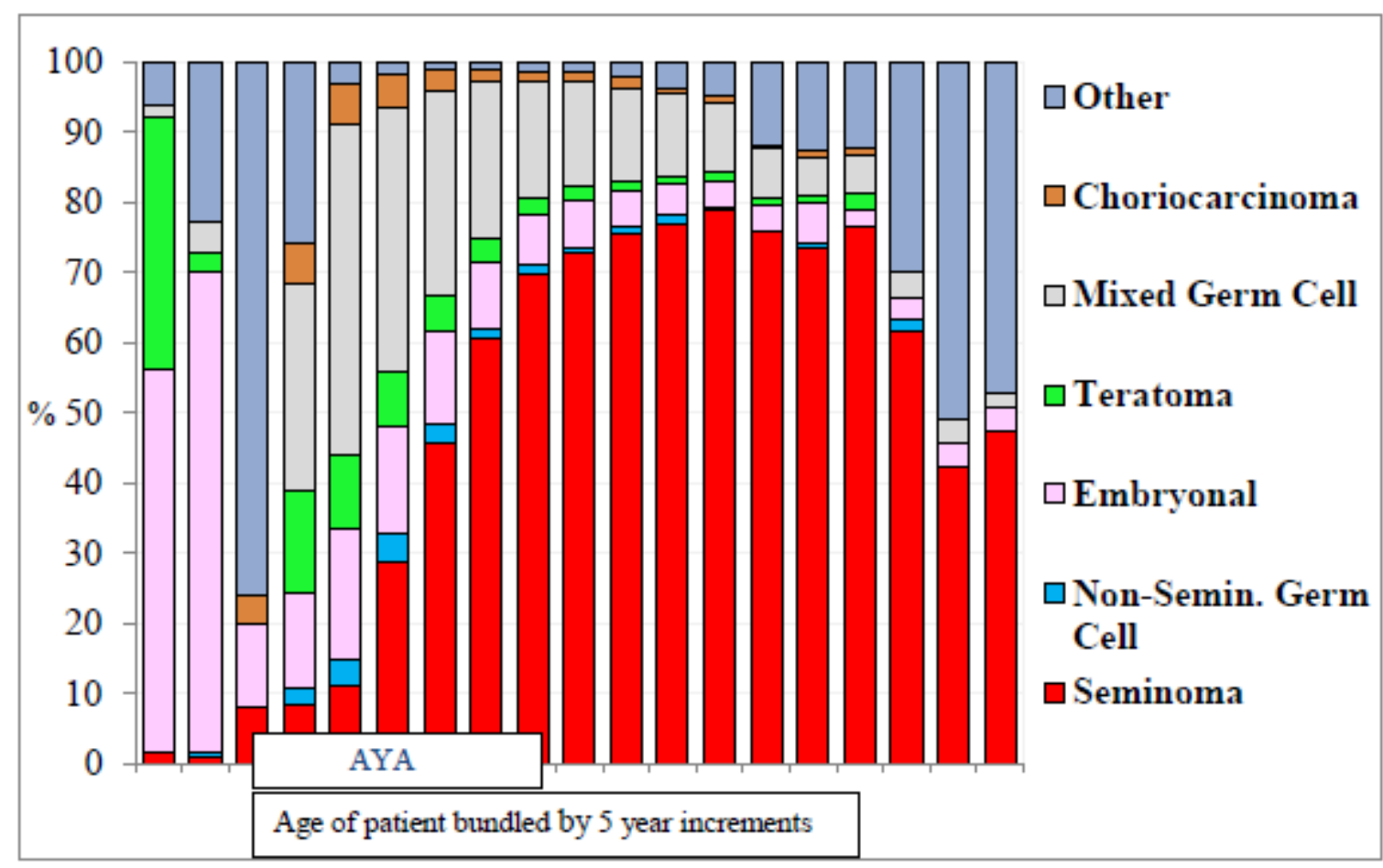

818

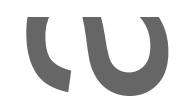

819 FIGURE 1 Histology Distribution of Testis Cancer, 2000-2011, SEER18, by Age

820

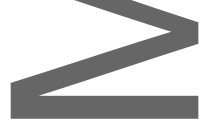

821

822

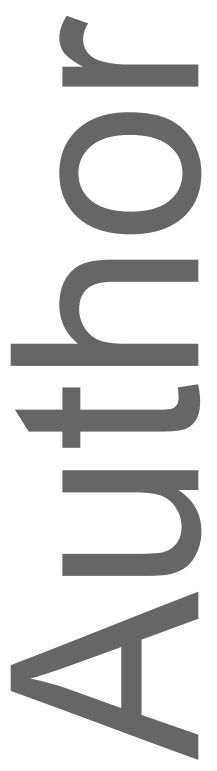

This article is protected by copyright. All rights reserved. 


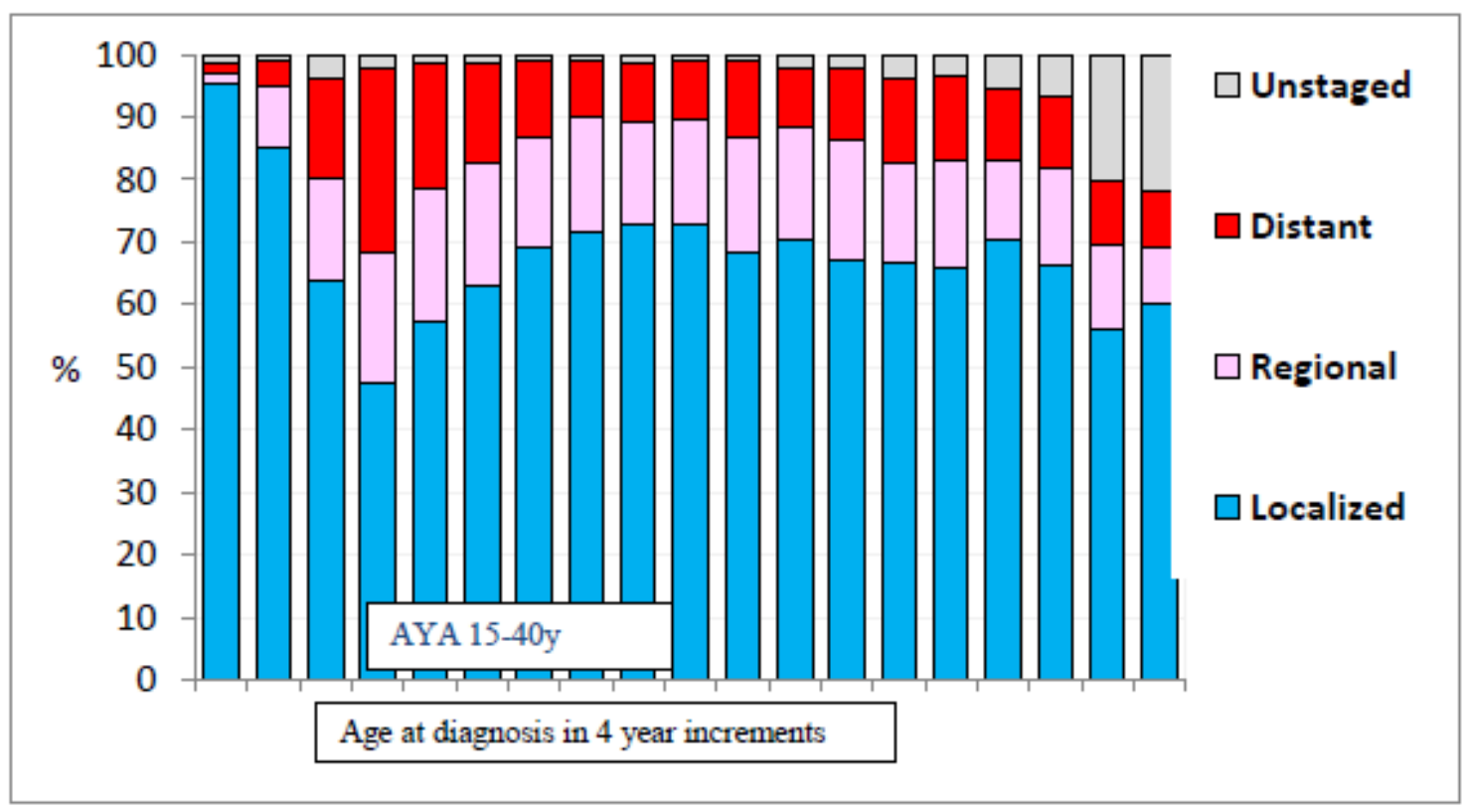

823

824 FIGURE 2 Distribution of Stage of Testis Cancer, SEER 18, 2000-2011, by Age

825

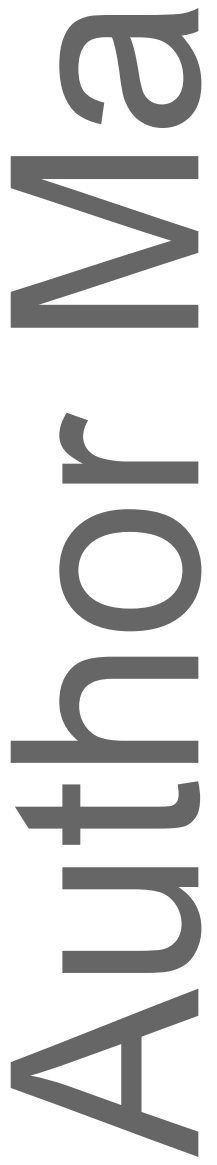

This article is protected by copyright. All rights reserved. 


\section{University Library}

\section{- M M I N E R VA A gateway to Melbourne's research publications}

Minerva Access is the Institutional Repository of The University of Melbourne

Author/s:

Stoneham, S;Murray, M;Thomas, B;Williamson, M;Sweeney, C;Frazier, L

Title:

AYA testis cancer: The unmet challenge.

Date:

2019-08

Citation:

Stoneham, S., Murray, M., Thomas, B., Williamson, M., Sweeney, C. \& Frazier, L. (2019).

AYA testis cancer: The unmet challenge.. Pediatr Blood Cancer, 66 (8), pp.e27796-. https:// doi.org/10.1002/pbc.27796.

Persistent Link:

http://hdl.handle.net/11343/285841 